\title{
List of Plants collected in Mt. Hakusan and its Vicinities.
}

(Continued from p. 102.)

\section{Tsutsumi Ichimura.}

\section{Hamamelidaceae.}

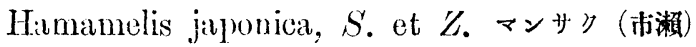

\section{Rosaceae.}

Cydonia japonica, l'ers. var. pygmaea，Max.クザ（畕坐谷） Geum

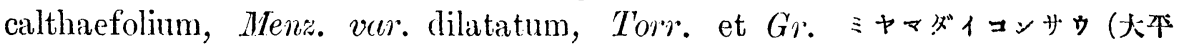
别山祠） G. dryadoides, S. et Z. チングルマ(同上) * G. japonicum, Thunb. ダイコンサゥ(慶松本) Pirus sambuciforia, Ch. et Schl。ミヤマナカカマド（仙人笜） P. aucuparia, Gaertn. var. japonica, Max.ナかマド(指尾) P. gracilis, S. et $Z$. ナンキンナ・カマド (櫌松本) Pourthiaea villosa，Dcne. ウシコロシ（女原） Rubus rosifolius, Sm. バ円イチゴ (吉野. 白峰) R. pectinellus, Max.マルバフ ンイチゴ（市瀨） R. spectabilis, Pursh ※シバナイチゴ（大平） R. japonicus，

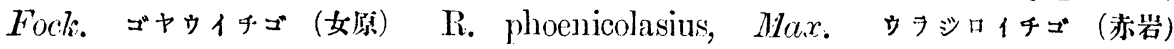

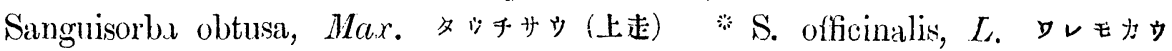
(鶴來) Spiraea kamtschatica, Pall.ナッュキサッ（吉些）

\section{Leguminosae.}

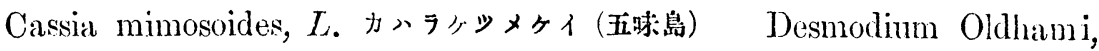
Oliv. フダカンザ（女原） Desmodium podocarpum, DC. var. japonicum, Max.

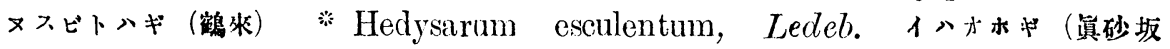
Indigofera tinctoria, L. コマッナギ (吉野) I. decora, Lindl. ニハフヂ(䳡来) Lathyrus Davidii, Hce.イタ千少・ゲ(女源. 吉野) *Pueraria Thunbergiana, Benth.クメ(术瀨) * Sophora flavescens, Ait. クラ・(吉野) Vicia nnijuga, Al. $B r$. タニヌタシ (吉野)

\section{Geraniaceae.}

Geranium davuricum, $D C$. ヘクサンフウロ(上走. 犬平) G. nepalense, Swect.アカバナゲンフショッコ（女原） 


\section{Oxalidaceae.}

Oxalis Acetosella, $I$. ミャマカタッミ(音生谷. 別) O. violacea, $L$. ムラサキカタパ（同上）

\section{Polygalaceae.}

Polygala jajonica, Houtt. ヒメハギ（五味島）

\section{Euphorbinceae.}

Aleurites japonica, $B l$. ププラギリ(白峰) Daphniphyllum glaucescens, Bl. ヒメュッ゙クハ(音生谷. 别) * Euphorbia lasiocaula, Boiss. ハクサンタイケ゚キ (同上) E. adenochlora, Mor\%. et Dcne. ノゥルシ(女原) * E. Sieboldiana, Moor. et Dcne. ナッタゥダイ(上走) E. humifusa，Willd.ニシキサウ(鶴來) Flueggea japonica, Müll. Arg. 七トッハハギ(赤岩)

\section{Empetraceae.}

Empetrum nigrum, $L$. ガンカサシン (大本. 飛彈室堂)

\section{Coriariaceae.}

* Coriaria japonica, A. Gr. ドクッッキ(女原)

\section{Aquifoliaceae.}

Ilex Sugeroki, Max. クロソョゴ (上走) I. rugosa, Fr. Schm. ッルッァ (音坐谷. 别)

\section{Anacardiaceae.}

* Rhus semi-alata, Th\% var. Osbeckii, $D C$. フシノキ(贽野) R. trichocarpa, Miq. ヤマシルシ (六万山)

\section{Celastraceae.}

Celastrus flagellaris, Rupn. イハシメッ゙ル (女原) C. articulatus, Thunb. ッルウメもドキ(鶴来) Fuonymus europaea, I. var. マェミ（嗇生谷) E. melanantha, $F r$. et $S a v$. サハダリ (音生谷) E. alata, K. Koch. var. subtriflora, Fr.

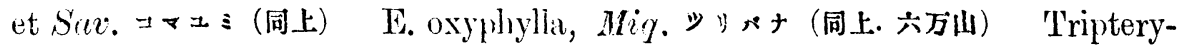
gium Wilfurdi, Hook. クロッ゙ル (赤花)

\section{Aceraceae.}

Acer splicatum, Lam. var. ukurunduense, $M(a x$. ギラボナ（甶生谷. 别) A. crataegifolium, $S$. et $Z$. ククカヘデ (同上. 白峰) $A$. rufinerve, $S$. et $Z$. ウリハダカヘデ（同上） A. pictum，Thunb.トキワカへデ（白峰）

\section{Staphyleaceae.}

Staphylea Bumalda, $S^{r}$. et $Z$. ミッバゥッギ (贽野. 白峰) 


\section{Balsaminaceae.}

Impatiens Textori, Miq. ッッファサウ(鶴来. 蓄生谷) I. nolitangere, $I$. キッリフ子(同上)

\section{Rhamnaceae.}

Berchemia ricemosa, S. et Z. クマヤナギ(女原) Rhamnus davmicns, Pall。アネハダ(同上) R. crenata, S. et Z.インノキ(音生谷. 别)

\section{Vitaceae.}

Vitis, flexunsa, Thunl. ギョッジノミッ゙ (市糈) V. Coignetiae, Pull.

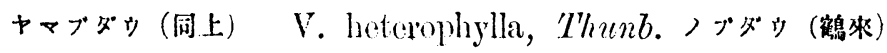

\section{Dilleniaceac.}

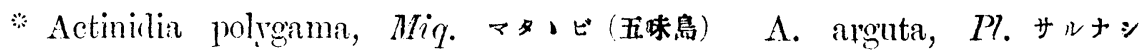
(女原)

\section{Theaceae.}

Stewartia psendo-Camellia, Max, ナッ、メキ(如原)

\section{Stachyuraceae.}

Stachyurus prinecox, S. et Z. キフヂ (女原)

\section{Guttiferae.}

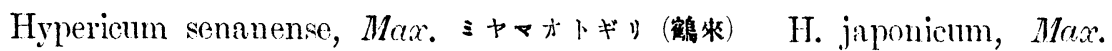
ヒメカトギリ（同上） Ir. erectum，T'tunh. 扑ギリサウ（同.上） H. Ascron, $L$. トモエサカ(白峰)

\section{Tiliaceae.}

Tilia cordata, Mill. valr. japonica, Miq. シナノキ(䡒生谷. 指)

\section{Bixaceae.}

Idesia polycarpa, Max.イ・ギ（书）瀨）

\section{Violaceae.}

Viola biflora, $I$. キバナノコマノッメ(大平) V. sylvestrie, Kit. var.

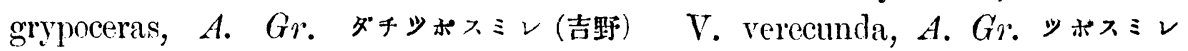
(同.上)

\section{Onagraceae.}

Circaea alpina, $L$. ミヤマタ二タデ (青生谷. 别) C. erubescens, $F r$. et Sav.タニタデ（同上） C. quadrisulcata, Max. ミジタマサウ（同上） Epilobium

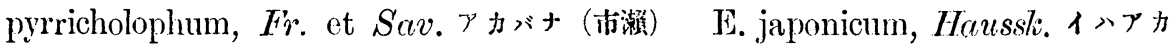
パナ（大平） E. dahuricum, Fisch。ヒメフカボナ(凅生谷)

\section{Araliaceae.}

*Aralia repens, Mackino. トチバニンジン (者生谷, 別)， A. cordata, Thund). ウド (女原. 白峰) Acanthopanax ricinifolium, $S$. et $Z$. ハyキy (畜生谷. 別) 


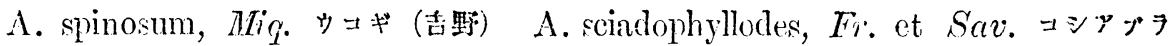

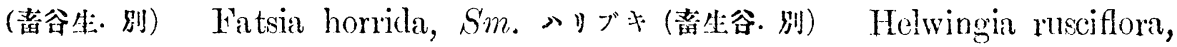
Willd. ハナィカダ (女原)

\section{Umbelliferae.}

*Angelica Florenti，Fr. et $S a v$. ショ子ニンシン(上走. 㗰㕹) Bupleurum murtiverve， $D C$. ハクサンサイコ (䗥咙. 别山室堂) Chamaele tenera, Miq.

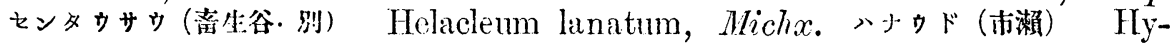
drocotyle javanica，Thunb.オホハチドメグサ（䳽來） Ligusticum acutilobum, $S$. et $Z$. タタキ (上走) Osmorhiza japonica, $S$. et $Z$. ヤナ゙ニンジン (同上) Pencedanum multivittatum, Max。 ハクサンホゥフォ（上走） P. terebinthaceum, Fisch. ヤマニンジン

\section{Cornaceae.}

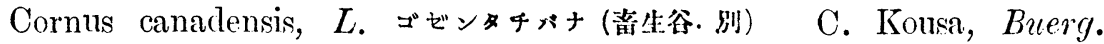
ヤマハッシ (女原) C. macrophylla, W'all. ミジキ(鹤兆) Marlea platanifolia $S$. et $Z$. サリノキ(音生谷. 別)

\section{Clethraceae.}

* Clethra barbinervis, S. et Z. リヤシブ

\section{Pirolaceae.}

Chimaphila japonica, Miq. ムメがササ（同上） Monotropa uniflora

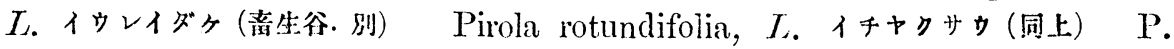

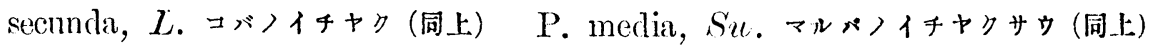

\section{Ericaceae.}

Andromeria campanulata, Miq. フッリンッンシ (蓄生谷. 别) A nana,

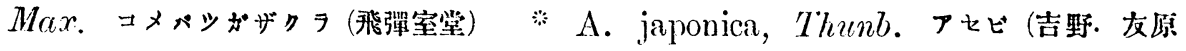
Gaultheria adenothrix, Max. アカモ) (鶴來) Leucothoe Grayana, Max.

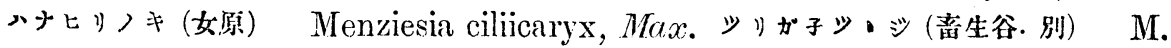
pentandra, Max. コヤゥタクッ・シ（同上） Phyllodoce taxifolia, Salisb. ツがザクタ(饿彈室堂. 大平) Tripetaleia paniculata，S. et Z. ホッ、シ（女原) T. bracteata, Max. ヘコッ・シ (同 t) Tsusiophyllum Tinakae, Max. コメッ ・シ（上走） Rhododendron brachycarpum, I)on. ハクサンシャクナゲ(上走 Vaccininum japonicum, Miq. アクシバ(鶴粉) V.ovalifoium, Sm. クロウフヌ

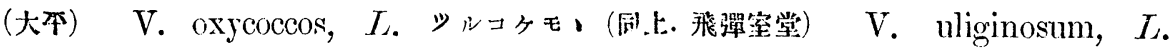

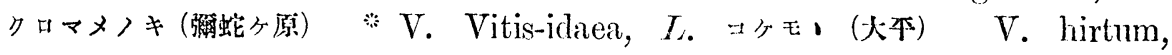

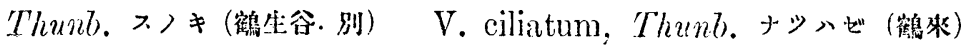

(To be continued.) 